\title{
New Science for a Secure and Sustainable Energy Future
}

A report of a subcommittee to the Basic Energy Sciences Advisory Committee 

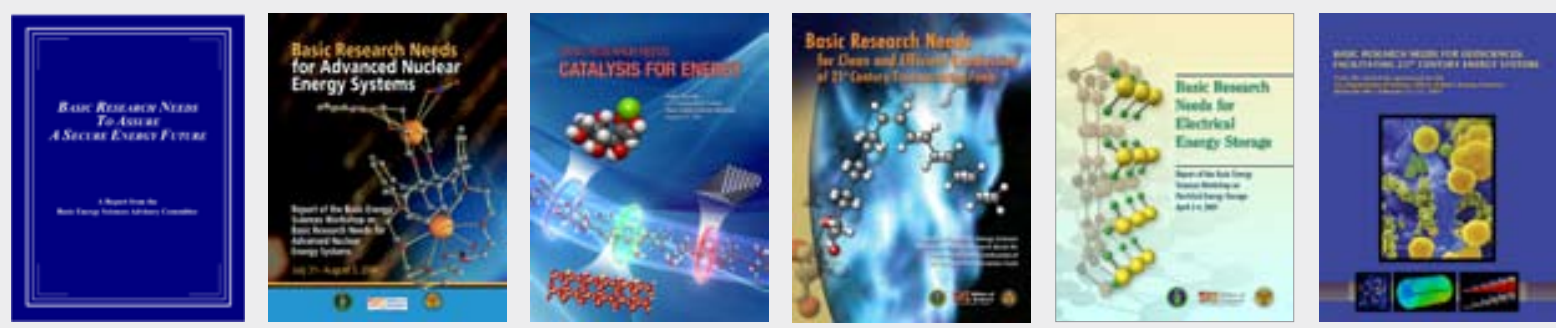

\section{About This Report}

Over the past five years, the Department of Energy's Office of Basic Energy Sciences has engaged thousands of scientists around the world to study the current status, limiting factors and specific fundamental scientific bottlenecks blocking the widespread implementation of alternate energy technologies. The reports from the foundational BESAC workshop, the ten "Basic Research Needs" workshops and the panel on Grand Challenge science detail the necessary research steps (http://www.sc.doe.gov/bes/reports/list.html).

This report responds to a charge from the Director of the Office of Science to the Basic Energy Sciences Advisory Committee to conduct a study with two primary goals: (1) to assimilate the scientific research directions that emerged from these workshop reports into a comprehensive set of science themes, and (2) to identify the new implementation strategies and tools required to accomplish the science.

From these efforts it becomes clear that the magnitude of the challenge is so immense that existing approaches - even with improvements from advanced engineering and improved technology based on known conceptswill not be enough to secure our energy future. Instead, meeting the challenge will require fundamental understanding and scientific breakthroughs in new materials and chemical processes to make possible new energy technologies and performance levels far beyond what is now possible.
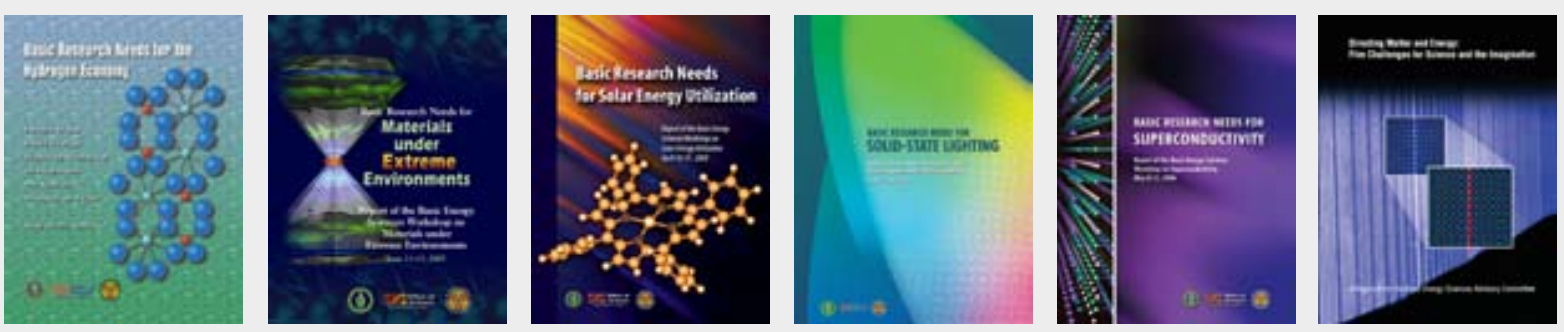

\section{On the Cover}

A stylized image of the carbon nanotube, a remarkable and versatile material discovered in the 1990s. Composed of hexagonal sheets of carbon atoms rolled into a tube with a diameter on the order of one nanometer, carbon nanotubes have 100 times the strength of steel but only one-sixth the mass density. They can be made single wall or multi-wall, metallic or semiconducting, and are poised to play central roles in catalysis, conversion of sunlight to electricity, and electrical energy storage. Discovered by basic research, carbon nanotubes represent the kind of complex functional materials that are essential to enable the new energy technologies required for a sustainable and secure energy future. 


\title{
New Science for a Secure and Sustainable Energy Future
}

\author{
A Report from the \\ Basic Energy Sciences Advisory Committee \\ Chair: \\ John Hemminger \\ University of California, Irvine \\ U.S. Department of Energy
}

December 2008

Prepared by the BESAC Subcommittee on

Facing Our Energy Challenges in a New Era of Science

Co-chairs:

George Crabtree

Argonne National Laboratory

and

Marc Kastner

Massachusetts Institute of Technology 


\section{Basic Energy Sciences Advisory Committee}

Chair:

John Hemminger (University of California-Irvine)

Simon Bare (UOP LLC)

Nora Berrah (Western Michigan University)

Sylvia Ceyer (Massachusetts Institute of Technology)

Sue Clark (Washington State University)

Peter Cummings (Vanderbilt University)

Frank DiSalvo (Cornell University)

Mostafa El-Sayed (Georgia Institute of Technology)

George Flynn (Columbia University)

Bruce Gates (University of California-Davis)

Laura Greene (University of Illinois at Urbana-Champaign)

Sharon Hammes-Schiffer (Pennsylvania State University)

Michael Hochella (Virginia Polytechnic Institute)

Bruce Kay (Pacific Northwest National Laboratory)

Kate Kirby (Smithsonian Center for Astrophysics)

William McCurdy, Jr. (University of California-Davis)

Daniel Morse (University of California-Santa Barbara)

Martin Moskovits (University of California-Santa Barbara)

Kathryn Nagy (University of Illinois at Chicago)

John Richards (California Institute of Technology)

John Spence (Arizona State University)

Kathleen Taylor (General Motors, retired)

Douglas Tobias (University of California-Irvine)

John Tranquada (Brookhaven National Laboratory)

Designated Federal Officer:

Harriet Kung

Associate Director of Science for Basic Energy Sciences 


\section{New Science for a Secure and Sustainable Energy Future}

\section{Subcommittee on Facing our Energy Challenges in a New Era of Science}

Co-chairs:

George Crabtree (Argonne National Laboratory)

Marc Kastner (Massachusetts Institute of Technology)

Simon Bare (UOP LLC) ${ }^{\star}$

Michelle Buchanan (Oak Ridge National Laboratory)

Andrea Cavalleri (Oxford University, UK)

Yet-Ming Chiang (Massachusetts Institute of Technology)

Sue Clark (Washington State University)*

Don DePaolo (Lawrence Berkeley National Laboratory)

Frank DiSalvo (Cornell University)

Wolfgang Eberhardt (BESSY-Berlin)

John Hemminger (ex officio, University of California-Irvine) ) $^{\star \star}$

Wayne Hendrickson (Columbia University)

Franz Himpsel (University of Wisconsin-Madison)

Michael Klein (University of Pennsylvania)

Carl Lineberger (University of Colorado)

Patrick Looney (Brookhaven National Laboratory)

Thomas Mallouk (Pennsylvania State University)

Michael Norman (Argonne National Laboratory)

Arthur Nozik (National Renewable Energy Laboratory)

Julia Phillips (Sandia National Laboratories)

John Sarrao (Los Alamos National Laboratory)

Technical Support:

Michael Casassa (Basic Energy Sciences)

Jim Horwitz (Basic Energy Sciences)

Roger Klaffky (Basic Energy Sciences)

Editorial Consultant

Dr. Al Hammond

* BESAC Member

${ }^{* *}$ BESAC Chair 



\section{New Science for a Secure and Sustainable Energy Future}

\section{Table of Contents}

Foreword 1

The Size of the Challenge 2

Imagining a Secure, Sustainable Energy Future 3

Materials with Unprecedented Performance 3

Making Chemical Change More Selective 4

Solar Power 4

Returning Carbon to the Earth 4

Safer and More Efficient Nuclear Power 5

Solar Fuels 5

Let There Be (Digital) Light 6

Electrical Energy Storage 6

A Solar Economy for Buildings $\quad 6$

Superconductivity and the 21st Century Electric Grid 7

A Hybrid Electrical Grid 8

Solid-State Lighting $\quad 8$

Advanced Transport $\quad 8$

Solar Fuels $\quad 8$

$\begin{array}{ll}\text { Electric Transport } & 9\end{array}$

Advanced Nuclear Energy Systems 9

Geological Carbon Sequestration 9

Making the Stories Come True $\quad 10$

Basic Materials Research to Commercial Impact 10

The Path to Success $\quad 11$

The Opportunity of Control Science 11

$\begin{array}{lr}\text { Recommendations } & 13\end{array}$ 



\section{New Science for a Secure and Sustainable Energy Future}

\section{Foreword}

The United States faces a three-fold energy challenge:

- Energy Independence. U.S. energy use exceeds domestic production capacity by the equivalent of 16 million barrels of oil per day, a deficit made up primarily by importing oil and natural gas. This deficit has nearly tripled since 1970.

- Environmental Sustainability. The United States must reduce its emissions of carbon dioxide and other greenhouse gases that accelerate climate change. The primary source of these emissions is combustion of fossil fuel, comprising about $85 \%$ of U.S. national energy supply.

- Economic Opportunity. The U.S. economy is threatened by the high cost of imported energy - as much as $\$ 700$ billion per year at recent peak prices. We need to create next-generation clean energy technologies that do not depend on imported oil. U.S. leadership would not only provide solutions at home but also create global economic opportunity.

The magnitude of the challenge is so immense that existing energy approacheseven with improvements from advanced engineering and improved technology based on known concepts-will not be enough to secure our energy future. Instead, meeting the challenge will require new technologies for producing, storing and using energy with performance levels far beyond what is now possible. Such technologies spring from scientific breakthroughs in new materials and chemical processes that govern the transfer of energy between light, electricity and chemical fuels. Integrating a major national mobilization of basic energy research - to create needed breakthroughs - with appropriate investments in technology and engineering to accelerate bringing new energy solutions to market will be required to meet our three-fold energy challenge. This report identifies three strategic goals for which transformational scientific breakthroughs are urgently needed:

\section{- Making fuels from sunlight}

- Generating electricity without carbon dioxide emissions

- Revolutionizing energy efficiency and use

Meeting these goals implies dramatic changes in our technologies for producing and consuming energy. We will manufacture chemical fuel from sunlight, water and carbon dioxide instead of extracting it from the earth. We will generate electricity from sunlight, wind, and high-efficiency clean coal and advanced nuclear plants instead of conventional coal and nuclear technology. Our cars and light trucks will be driven by efficient electric motors powered by a new generation of batteries and fuel cells.

These new, advanced energy technologies, however, require new materials and control of chemical change that operate at dramatically higher levels of functionality and performance. Converting sunlight to electricity with double or triple today's efficiency, storing electricity in batteries or supercapacitors at ten times today's densities, or operating coal-fired and nuclear power plants at far higher temperatures and efficiencies requires materials with atom by atom design and control, tailored nanoscale structures where every atom has a specific function. Such high performing materials would have complexity far higher than today's energy materials, approaching that of biological cells and proteins. They would be able to seamlessly control the ebb and flow of energy between chemical bonds, electrons, and light, and would be the foundation of the alternative energy technologies of the future. 
Creating these advanced materials and chemical processes requires characterizing the structure and dynamics of matter at levels beyond our present reach. The physical and chemical phenomena that capture, store and release energy take place at the nanoscale, often involving subtle changes in single electrons or atoms, on timescales faster than we can now resolve. Penetrating the secrets of energy transformation between light, chemical bonds, and electrons requires new observational tools capable of probing the still-hidden realms of the ultrasmall and ultrafast. Observing the dynamics of energy flow in electronic and molecular systems at these resolutions is necessary if we are to learn to control their behavior.

Fundamental understanding of complex materials and chemical change based on theory, computation and advanced simulation is essential to creating new energy technologies. A working transistor was not developed until the theory of electronic behavior on semiconductor surfaces was formulated. In superconductivity, sweeping changes occurred in the field when a microscopic theory of the mechanism of superconductivity was finally developed. As Nobel Laureate Phillip Anderson has written, more is different: at each level of complexity in science, new laws need to be discovered for breakthrough progress to be made. Without such breakthroughs, future technologies will not be realized. The digital revolution was only made possible by transistors-try to imagine the information age with vacuum tubes. Nearly as ubiquitous are lasers, the basis for modern day read-heads used in CDs, DVDs, and bar code scanners. Lasers could not be developed until the quantum theory of light emission by materials was understood.

These advances-high-performance materials enabling precise control of chemical change, characterization tools probing the ultrafast and the ultrasmall, and new understanding based on advanced theory and simulation -are the agents for moving beyond incremental improvements and creating a truly secure and sustainable energy future.

Given these tools, we can imagine, and achieve, revolutionary new energy systems.

\section{The Size of the Challenge}

It is clear that the ways in which the U.S. uses energy to power its cars, heat its homes, and fuel its industries are not sustainable. The U.S. dependence on imported oil is a primary challenge due to its pervasive impact on the economy and the threat to security should supplies be interrupted. The cost of imported oil, up to $\$ 700$ billion/year at recent peak prices, not only drives inflation across our economy but also drains precious resources that could be applied to pressing domestic problems like job creation and stabilizing credit markets. There is little prospect of relief in current projections of energy use: the U.S. demand for oil is expected to increase $15 \%$ by 2030 , and U.S. production has been declining steadily since 1975 . The solutions are painful but clear: cut down our imports by substituting alternative fuels for transportation and increase the efficiency of energy use.

Beyond the economic and security cost of imported oil, however, looms another challenge that many say is even bigger and more threatening: global climate change. Accelerated global warming threatens to alter many longestablished patterns of rainfall, temperature, ocean currents, and weather. Such changes could significantly alter the agricultural and economic networks that we have come to rely on. The economic cost of adjusting to these changes will be much larger than the preventive cost of reducing emissions.

Taken together, the dual problems of finding alternatives to oil use and reducing greenhouse gas emissions are daunting. Incremental changes in our energy systems cannot solve the problem. Entirely new ways of producing, storing and using energy are required, enabled by new materials and phenomena produced by use-inspired basic research. Tapping unused energy flows from the sun and wind, producing electricity without carbon dioxide emission from clean coal and high efficiency advanced nuclear power, storing electrical energy at high density, and using energy efficiently in solid state lights and fuel cells are all within reach given use-inspired basic research needed to overcome key scientific roadblocks. These roadblocks are substantial; they require new high-performing materials that orchestrate the seamless conversion of energy between light, electrons and chemical bonds. Such new levels of controlled chemical and physical complexity in materials require the innovations of basic research.

Beyond solving our domestic problems, there is a unique economic opportunity of marketing these next-generation energy solutions to the

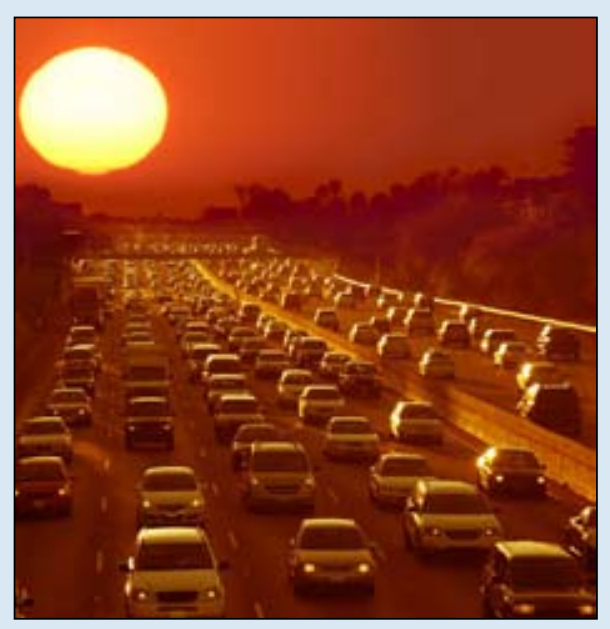

world. The global demand for energy is expected to double in the next 50 years, driven by the rising prospects of developing countries. The world faces the same energy and environmental challenges as the U.S.: a dependence on oil and the threat of global climate change. The innovative energy technologies that the U.S. develops for solving these problems will find ready and enduring markets throughout the world. We must, however, act quickly and decisively. Others see the same opportunities that we do, and there is a clear competitive advantage for the first mover. 


\section{New Science for a Secure and Sustainable Energy Future}

\section{Imagining a Secure, Sustainable Energy Future}

The United States faces growing dependence on high-cost imported oil, an urgent need to take leadership in reducing greenhouse gas emissions, and an economy under historic strain. Hardly the time for an ambitious attempt to lead a global revolution in energy technology?

Recall a time of similar peril on the verge of World War II when President Franklin D. Roosevelt launched a wave of national investment into what were at the time unproven approaches, leading to the massive mobilization of scientists, engineers, and industrialists that led to radar, harnessing the power of the atom and other technologies - and the scientific base on which they rested-that gave the U.S. a decisive edge, not just in war, but in the global peacetime economy that followed.

Might a similar science and technology mobilization be just what is needed to address today's problems? Could it help jump-start the economy and generate millions of new jobs in an expanding sustainable energy industry? Free the U.S. from the national security threats and the huge drain on our economy of imported oil? Reclaim our national reputation and our global technology leadership with a revolutionary wave of clean energy technologies that address the threat of global climate change and capture the burgeoning global market for high technology energy solutions?

Just as with the Manhattan Project or the later Apollo effort to reach the moon, the outcome is not certain, but the prospects-grounded in remarkable new capabilities for controlling complex materials and chemical processes, growing entrepreneurial enthusiasm, and careful scientific assessments of what might be achieved-are almost as breathtaking as those that confronted President Roosevelt and President Kennedy.

What are those prospects? What might a $21^{\text {st }}$ century energy industry look like, and what implications would it have for our lives and those of our children and grandchildren? In the scenario that follows, we explore what might be possible if we focused the full attention of the country's best research talent, most innovative engineers, and most visionary entrepreneurs on creating a new energy future.

\section{Materials with Unprecedented Performance}

Just for starters, imagine if the steel and other materials that form our nuclear reactor vessels and coal-fired boilers were created not by traditional bulk processes but through new processes that controlled properties at the nanoscaleeffectively, almost atom by atom. The result could be materials that promote self-healing of stresses or with unusual surface properties that resist chemical corrosion. As a result, the material's strength and resistance to damage would be sharply increased, and the time to failure might be almost 10 times longer than for conventional materials-and much more reliably known. That means that a nuclear reactor could operate not at $330^{\circ} \mathrm{C}$ and $34 \%$ efficiency, but at $1000^{\circ} \mathrm{C}$ and $50 \%$ efficiency. Similar changes could make possible coal-fired plants operating at $60 \%$ efficiency, or cars made from ultra-light weight materials that require less energy to propel and thus cut gasoline consumption by a third. This is hardly science fiction: novel materials like carbon nanotubes that 
have 100 times the strength of steel but only one-sixth the weight are already known in the laboratory. The challenge is to understand the atomic and molecular origin of these remarkable properties and design them into practical materials.

To gauge the global impact, imagine that, over time, conventional, fossilfueled energy sources become nearly twice as efficient-cutting greenhouse gas emissions, perhaps even offsetting the higher consumption of fuel. Then apply that not just to the United States, but to the thousands of coal-fired power plants that India and China will build in coming decades.

\section{Making Chemical Change More Selective}

When we burn a fuel, or when we transform raw materials into fuels, chemical reactions occur. The problem is, there are many possible reactions-and most of those generate unwanted by-products and lower the overall efficiency. Living systems have evolved powerful, selective catalysts to control these reactions-producing by photosynthesis from sunlight, water, and carbon dioxide the energy and structural materials they need for growth. Man-made catalysts are important, too-we couldn't have artificial fertilizers, plastics, gasoline, and many other products without them. But today's man-made catalysts are relatively simple by comparison with Nature's, and are discovered, not designed.

With nanoscale science-understanding how chemical reactions can be controlled at an atomic scale-we have the opportunity to move far beyond today's catalysts. That's because reactions on a catalyst can be controlled by structure near the surface, creating new opportunities to control both the speed of the reaction and its course-which products, out of many possible, are produced. To give just one example of how differently materials behave at nanoscale, consider

\section{Solar Power}

Solar power is in rapid growth mode; new manufacturers and installers of photovoltaic solar cell systems are cropping up everywhere. With present technologies, even assuming continued rapid growth, solar cells are predicted to only supply about $5 \%$ of the huge amount of carbon-free energy we will need by 2050 . The challenge for the United States is to produce solar power at a cost less than coalbased electricity-a factor of 10 better than we can do today.

Most present production of solar power is based on crystalline silicon cells, the first generation technology. The second generation, now starting to be commercialized, is based on thin-film cells and cells made from inexpensive oxide semiconductor materials coated with light sensitive dyes and from photoactive organic polymeric materials. These approaches may yield much lower costs, but at present have significantly lower conversion efficiencies.

The game-changing breakthrough needed from third generation cells is both lower cost and very high conversion efficiency. New paradigms for photon capture and conversion are needed to meet this goal. Presently, very high efficiency solar cells can be produced by combining different semiconductor materials in a tandem cell structure so as to capture far more of the energy in sunlight. However, the cost per unit area of these cells is 200 times more expensive than first generation cells. Basic research is necessary to maintain the high efficiency of tandem cells while lowering their cost by exploring new materials, novel structures, and the

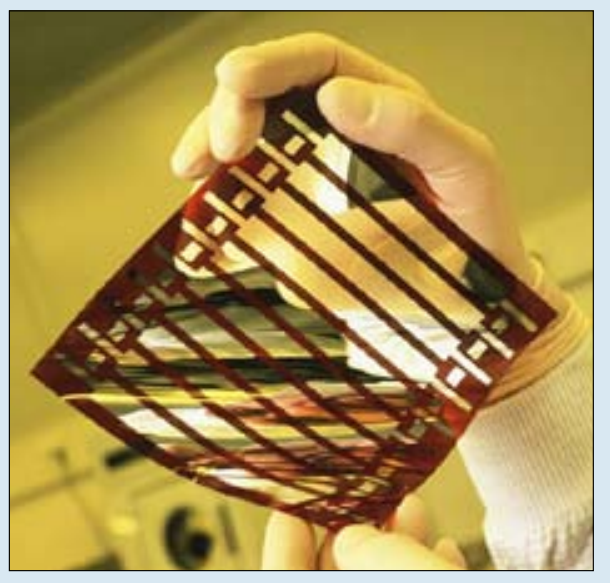

Organic materials promise inexpensive flexible solar fabric for powering personal electronics or for integration into buildings. Source: BES Solar Report, Konarka Technologies

use of unique solar concentrators. Another approach to third generation solar cells is based on so-called quantum dot solar cells, made from semiconducting nanocrystals arranged in unique configurations that alter and enhance the absorptive and electron-producing properties of semiconductors like silicon in dramatic ways. Third generation solar cells are still in the early stages of scientific exploration and we don't know how to make cells that show the promised high efficiency and low cost sufficient to beat the cost of electricity from coal. However, the opportunity is huge; third-generation cells can in principle greatly exceed the theoretical limit of conversion efficiency for first and second-generation designs. Using new materials and hybrid designs, they can dramatically lower the cost of solar electricity. gold, called the noble metal because it's famously impervious to chemical reactions. In defiance of conventional wisdom, research has found that nanoscale clusters of gold are highly reactive and can be very powerful catalysts for removing carbon monoxide from hydrogen.

So imagine that we can design catalysts that mimic those nature has created or even learn to do better.
Why not use energy from the sun to make fuels, like plants do? Why not combustion in our power plants that doesn't emit pollutants?

\section{Returning Carbon to the Earth}

The emissions from thousands of new coal-fired power plants-even if they operate at higher temperatures and with greater efficiency-represent a 


\section{New Science for a Secure and Sustainable Energy Future}

potential climate disaster. And since coal is the most abundant fossil fuel on Earth, we need to find a way to burn it without the release of carbon dioxide into the atmosphere. One opportunity is to capture the carbon dioxide gas from combustion, compress it, and inject it into the ground in places where geological formations can trap it and store it safely away from the atmosphere. The last part is especially tricky, presenting a barrier that basic science needs to overcome. For example, how do we ensure that the gas doesn't displace subsurface brine in ways that could impact underground sources of drinking water and that it stays put long enough-centuries, at least? Part of the answer is controlled, large-scale trials. But such trials are a shot in the dark without studies of the chemistry of carbon dioxide-brine mixtures and how they react with porous rocks at depth-nanoscale phenomena again-combined with advanced computation. Just as we now find and manage the extraction of oil from deep reservoirs with simulation tools, we can learn to simulate the reverse process, too; to sequester the greenhouse gases generated from burning fossil fuel deep underground. Even capturing and separating the carbon dioxide for sequestration is tricky. Highly selective and energy efficient processes, on an enormous scale, will require new materials that direct the chemistry of carbon capture and separation at the molecular level.

So imagine that a third or even half of the projected emissions from fossilfueled power stations are eventually put safely underground. That would be real progress, but not nearly enough by itself. We also have to find ways to use electricity more efficiently, and to generate it without fossil fuels.

\section{Safer and More Efficient Nuclear Power}

One way to make electricity without fossil fuels is already on the grid: nuclear power. But nuclear power could potentially be much more efficient and safer to boot. The key is both new reactor concepts and new complex materials with controlled, predictable properties, capable of withstanding more intense radiation damage, chemical corrosion and higher temperatures. But it's not just new reactors that will be part of a nuclear renaissance. More safety will come from advanced reactor designs that are inherently safe and from computation tools that can accurately model the complexity of nuclear processes, both those that occur in a millionth of a nanosecond as atoms split within a reactor and gradually over a thousand years as radioactivity slowly decays in a nuclear waste storage facility. And we can burn the nuclear waste in fast reactors that reduce its volume by a

\section{Solar Fuels}

Making fuels from sunlight, water, biomass, and carbon dioxide is an important way to free the world from the environmental consequences of fossil fuels. Efforts to expand use of plant-derived ethanol, biodiesel, and other biofuels are already underway. This approach is feasible in moderate quantity, but the production of cornbased biofuels at very large scale is probably not sustainable because it competes with food production. Therefore, we must learn to make hydrogen or other solar fuels by using sunlight to split water or photoreduce carbon dioxide with water, just as plants do in the process of photosynthesis.

One approach is to imitate photosynthesis with non-biological materials, which requires a more profound understanding of the chemistry of plant life. If we can replicate plant biochemistry on an industrial scale, probably with the aid of powerful new catalysts, then we might be able to build solar-powered refineries whose feed- stock is water and carbon dioxide, not petroleum. A second approach is based on the solar cell model, capturing photons in semiconductor materials submersed in water and using the electronic charges they produce to split water, so that the cell produces hydrogen instead of electricity. The challenge here is to design and discover novel nano-engineered materials that split water with sunlight and are also cost effective, efficient and stable. A third and even more ambitious approach is to artificially connect biochemical systems that can combine water, sunlight, and even carbon dioxide to produce hydrogen or perhaps another clean fuel in a man-made chemical reactor. The key here is identifying the "software" for the synthetic cell, which can guide the process to produce the desired product. All three of these approaches lie just beyond the horizon of present scientific knowledge, but the technical issues and promising research directions to overcome them are in clear focus.

\section{Splitting Water with Sunlight}

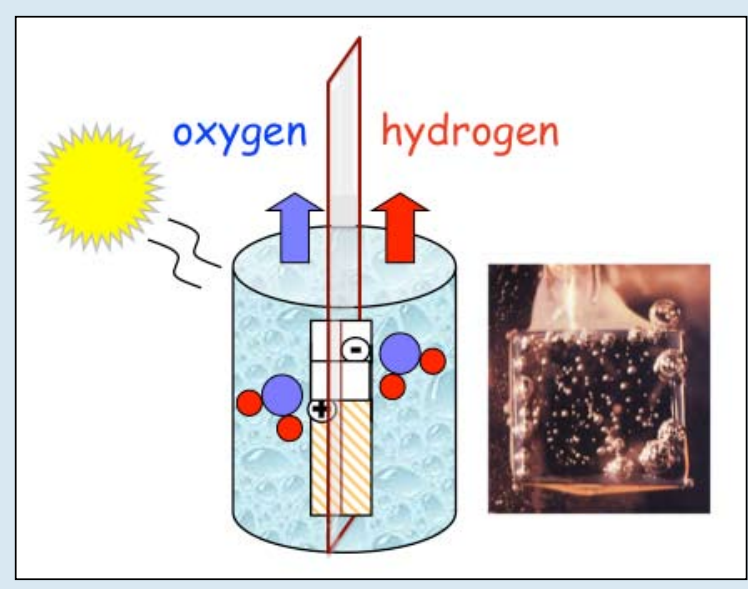

Splitting water with sunlight produces hydrogen renewably in the laboratory. Complex catalysts that control the water-splitting chemistry at the electrode-water interface are needed to break the commercial technology barrier. Sources: Nate Lewis, Art Nozik, George Crabtree 


\section{The Challenged Electricity Grid}

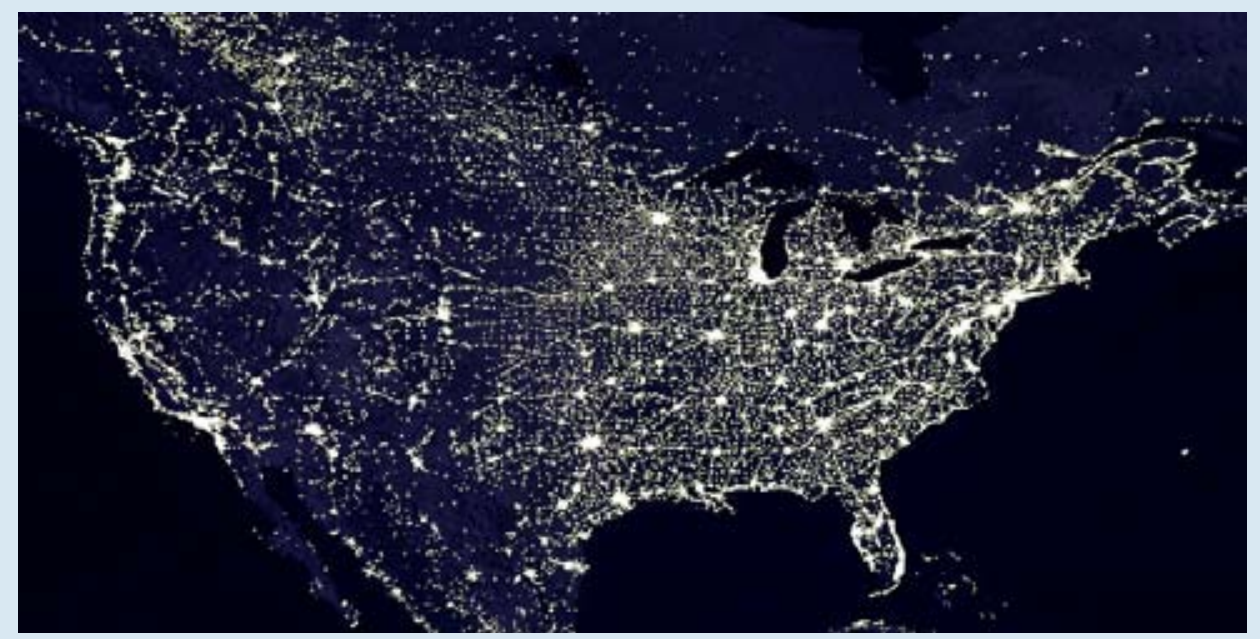

The electricity grid faces challenges of saturated capacity in cities and suburbs and of increasing standards for power quality and reliability. Further, the highest potential sources of solar and wind energy are not near the places of highest demand. We need more effective long distance transmission of electricity. factor of 10 or more; these could be implemented provided we can find methods through science to prevent the bomb-grade by-products of reprocessing fuel from falling into the wrong hands. It's about managing the entire fuel cycle through sciencebased, predictive processes rather than through old-fashioned administrative controls and engineering specifications.

\section{Let There Be (Digital) Light}

How can we use power more efficiently? How about shrinking the $22 \%$ of all electricity that now goes to lighting homes, offices, and streets to less than $2 \%$ ? And while we're at it, imagine not just that naked light bulb (even if it is a compact fluorescent one), but light that is far more sophisticated, directed where we want it, colored or incorporating special effects when we desire. The answer is solid state lights, the progeny of the little lightemitting diodes that adorn our digital tools. That naked incandescent bulb generates mostly heat and is only $5 \%$ efficient as a light source. In principle, solid-state lights could reach $70 \%$ efficiency-if nanoscale science can produce defect-free composite semiconductors-and, since they come with digital controls, do anything you might desire, such as a wall of light that spells out your advertisement in a flowing script. But mostly, solid-state lights can so far outstrip both incandescent and those inelegant fluorescent lights that we have to have them. This requires accelerating the science of these new devices.

\section{A Solar Economy for Buildings}

Lights are a good start, but why stop there? Imagine if nearly every new commercial and residential building in the country (and many retro-fitted existing buildings) incorporated solar cells in roofing or windows and used the power directly or fed it back to the electrical grid. Not today's solar cells-but tomorrow's, made of ad- 


\section{New Science for a Secure and Sustainable Energy Future}

\section{Superconductivity and the $21^{\text {st }}$ Century Electric Grid}

Ever had the power go out-even for a few minutes-causing you to lose your work on a computer? Now multiply that times millions of people and billions of dollars in commercial and industrial operations. In a digital age, such micro-outages are even more costly than the infamous blackout of much of the Northeastern U.S. a few years ago. Small-scale outages caused an $\$ 80$ billion hit to the U.S. economy in 2006 alone. We increasingly depend on the grid to provide not only electricity at the flip of a switch, but power that won't fluctuate enough to crash or damage our many digital devices. Yet at present, the reliability of the U.S. grid is $5-10$ times less than that of, say, France or Japan.
That's where superconductivity could play a major role. Some engineers envisage superconducting "beltways" around major cities, new high-capacity superconducting cables in existing underground conduits to bring up to five times the electricity into our power-hungry cities, and new superconducting links at many places in the grid to stabilize its performance and lower transmission loses.

But we still don't understand why the most complex materials become superconducting at the highest temperatures, and thus we cannot design the next generation of superconductors for even better performance. There is potential to increase tenfold the amount of current a superconducting wire can carry. So, advanced research will pay big dividends, moving us from small-scale trials to superconductors robust and cheap enough to anchor a $21^{\text {st }}$ century electrical grid. Both the development of new theoretical concepts and the investigation of new classes of materials-such as a recently discovered family of iron-based superconductors-are needed, and progress in the field is accelerating. There is wide-spread expectation that controlling the properties of superconducting materials at the nanoscale, exploiting a wide variety of research and fabrication techniques now emerging in laboratories across the country, will be the key to increasing both operating temperatures and current-carrying capacity.

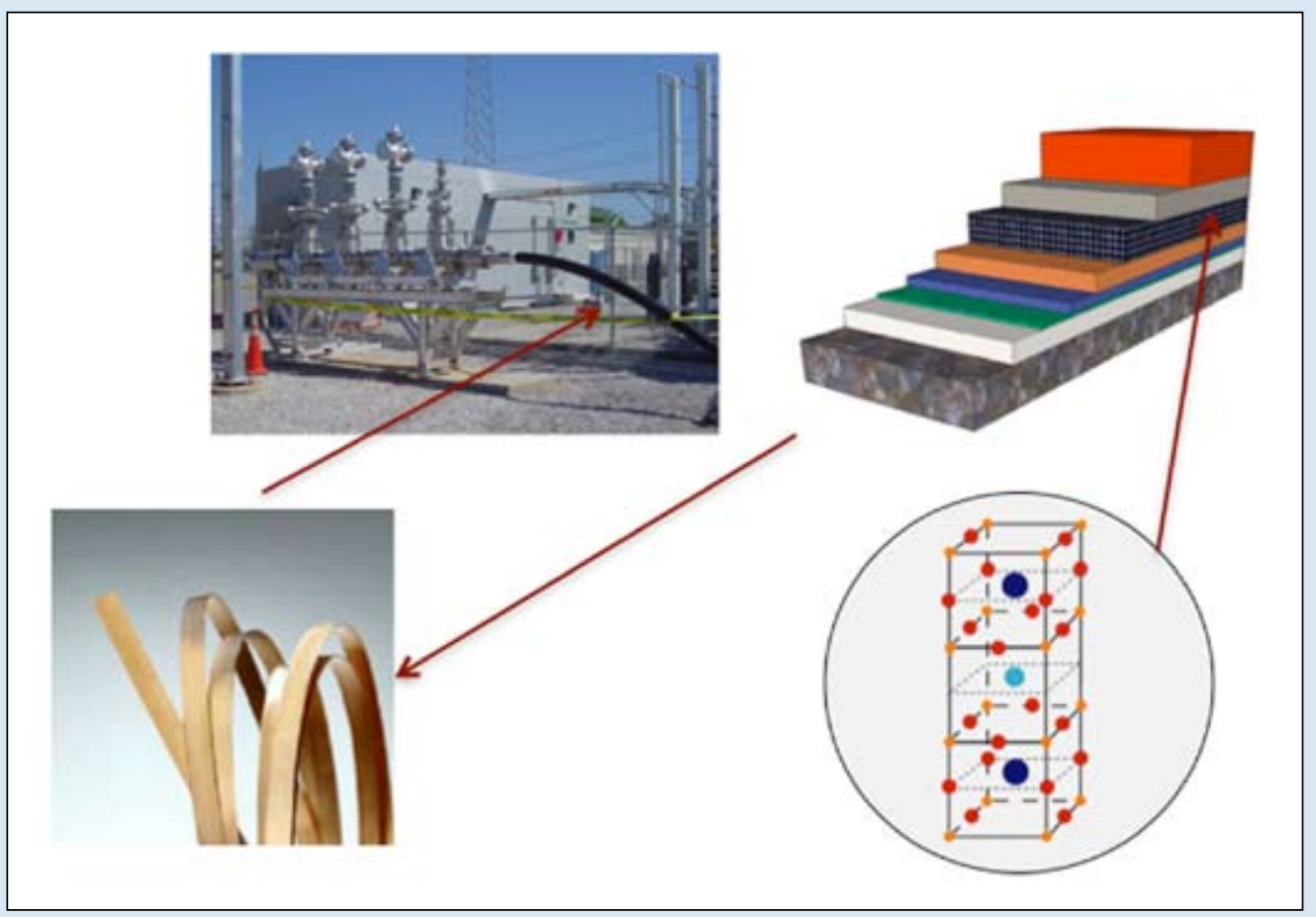

Complex materials drive next generation energy technologies. The superconductor yttrium barium copper oxide requires coordination of four elements in an intricate structure with designed defects at the atomic level, and coordination of the superconducting material with other functional layers to assemble kilometerlong superconducting cables. These cables can deliver five times more electrical power than conventional cables to cities and suburbs.

vanced materials that can capture far more of the energy in sunlight and are both much more efficient and less costly than at present. Such solar cells have already achieved $41 \%$ efficiency in the laboratory, showing that unprecedented performance can be achieved with innovative complex functional materials. These laboratory cells, however, are not ready for prime time: research is needed to dramatically reduce the cost of the materials and construction of these cells if they are to compete in the marketplace. Other kinds of solar cells based on inexpensive organic materials also promise low cost solar electricity, but only if the materials can be made nearly defect-free to convert virtually all of the solar-generated electrons into useful power. Solar power is already on a roll and likely to advance, but getting to the point where it can compete with or displace coal-fired power plants will require fundamental new knowledge. Imagine that solar, wind energy and perhaps other renewable sources of clean electric power could generate at least a third of our electricity and ultimately, much more. 


\section{A Hybrid Electrical Grid}

What happens at night or when the wind stops? Well, the grid will react to that change. Our $21^{\text {st }}$ century grid will be a more tightly interconnected hybrid entity with superconducting links to increase capacity, lower transmission losses and stabilize performance-even micro-outages are too costly in a society dependent on its digital devices. But even more important, the $21^{\text {st }}$ century electrical grid will also incorporate huge amounts of fast-reacting energy storage coupled to the grid. This could be a new type of battery that operates by flowing a charged electrolyte from one tank to another across a charge/discharge stack and that can operate for decades; early prototypes are already in commercial operation, but they need to get a lot better and use less expensive, new materials. Energy storage that operates even faster than batteries could be achieved by supercapacitors that store charge directly in novel nano-engineered materials. Low-cost electrical energy storage will transform renewable energy sources from a bit player to a mainstream role in our energy economy, driving down greenhouse gas emissions from power plants to far below today's levels in the process.

\section{Advanced Transport}

Greening our buildings and our power sector is a good start. But we use even more energy-equivalent to all our imported oil-for transport. And it is hard to know which aspect of that situation is worse: the huge transfer of

\section{Solid-State Lighting}

In a digital age, ordinary incandescent lights are increasingly archaic and inefficient. Yet the future of $21^{\text {st }}$ century lighting is already apparent, in the tiny solid-state lights and indicators on many digital devices. The potential is for lights so long-lived that they will outlast your house; are as much as $70 \%$ efficient; and offer far more control over the color, quality, intensity, and directionality of light that they produce-an improvement in every way over both incandescent and fluorescent lights. A switch to solidstate lighting could reduce electricity use (and greenhouse gas emissions) in the United States by the equivalent of 100 large power plants.

To get there, we need to understand why materials that produce green light are so inefficient in order to make them better. Green light emitters, when combined with existing blue and red emitting materials, will give us the full spectrum, including pleasing forms of white light. To reach high efficiencies with solid-state lighting, we need to understand both the production of light within solid-state materials and how to get the light out of the device-which means control of materials at the atomic level, better knowledge of how electrons and other charge carriers move through materials, and new understand-

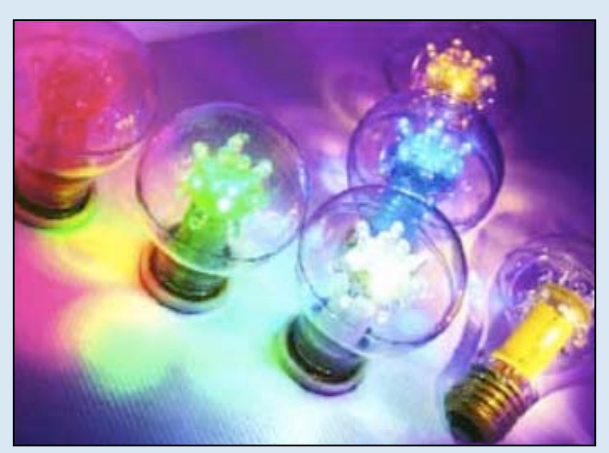

Solid state lights like these produce five to ten times more light-in a wider array of beautiful colors-than today's incandescent and fluorescent bulbs. Controlling the composition, defect structure, and interface phenomena of the semiconductors that produce this light is the key challenge for realizing their potential.

ing of how charge carriers recombine to produce light. Equally, we need to boost efficiency by such means as introducing periodic nanostructures-repeating atomic lattice patterns known as "photonic crystals," for exampleinto materials. Fundamentally, we need to better understand how light interacts with solid-state devices, find or create improved materials, and develop new methods for producing and processing them. wealth to oil-producing countries, the national security risks of that dependence, or the greenhouse gas emissions from our low-efficiency internal combustion engines. What are promising scenarios for phasing out petroleum fuels altogether?

To start with, hybrid vehicles are still in their infancy and could be made a lot more efficient. Even internal combustion engines-whether for hybrids or heavy trucks-could be perhaps $50 \%$ more efficient once we really understand combustion processes. Then, advanced biofuels could play a significant, if probably transitional, role. These are not today's biodiesel or grain-based ethanols, or even Brazil's more efficient sugar cane-based ethanol. Second generation biofuels will use all parts of a plant or an algae, and will come from specialized, high efficiency crops that don't compete with the food supply. But biofuels can probably never replace oil entirely and are likely most important as a bridge to the ultimate solution.

\section{Solar Fuels}

The ultimate transport solution would be solar fuels, made from using sunlight to split water and produce hydrogen, or to reduce atmospheric carbon dioxide and combine it with water to produce other clean solar fuels. Then the fuels, when burned or converted to electricity in a fuel cell, simply turn back into water and carbon dioxide. Plants and algae already do this in photosynthesis-they provide the proof of principle for the concept of fuels from the sun. So we might learn to mimic photosynthesis chemically, but alter the process to yield ethanol or another liquid fuel. Or we might develop new solar cell-like materials that capture light while submerged in water and use the electrons and holes they produce to do chemistry, splitting water to produce hydrogen. Perhaps even more radically, we may mimic nature's success by routing hydrogen ions produced by water split- 


\section{New Science for a Secure and Sustainable Energy Future}

\section{Advanced Nuclear Energy Systems}

Nuclear power holds great promise as a nearterm, carbon-neutral energy source. Realizing this potential requires confronting challenges such as disposal of nuclear waste, proliferation of nuclear weapons, and the sustainability of the present nuclear fuel cycle-along with continued improvements in the safety and efficiency of nuclear power. Underlying all of these areas is the basic scientific challenge of discovering and designing materials and chemical processes that can perform under extreme conditions. What materials, for example, can stand up to continuous bombardment by high-energy neutrons at intensities that rapidly degrade the best stainless steels? Or how do we monitor and control reactions that occur in one millionth of a nanosecond (within a reactor) and continuously over a thousand years (in a nuclear waste storage facility)?

Advancing the frontiers of materials science and chemistry will impact these challenges, benefitting nuclear energy and much else. Understanding how materials respond to radiation, very high temperatures, and a wide variety of corrosive substances is important not just for nuclear energy systems but for many other industrial processes such as high performance turbines. And it is clear that the ability to characterize and control the structure of materials at the nanoscale will be crucial to finding solutions, as will new computational tools that can model the resulting complexity so as to provide predictive tools for engineers. These research efforts will use advanced synchrotron X-ray sources, neutron sources, and supercomputers to transform the scientific understanding that underpins technology development for advanced nuclear energy systems. ting complexes to methane-producing complexes. The opportunities for bioinspired fuels and for innovative routes to produce them are virtually limitless. Such biochemical systems would combine sunlight, water, and carbon dioxide from the air to produce our fuels. This would be a true hydrogen or solar economy and would liberate humankind from fossil fuels forever.

\section{Electric Transport}

Solar fuels are not the only plausible scenario for transport. The other is the "plug-in" electric vehicle, probably a pure electric for in-town use, and a plug-in hybrid electric vehicle for longer trips. That way, super-efficient fossil or advanced nuclear power plants, renewable energy sources like wind and solar, and the hybrid electrical grid of the future become the dominant solution for transport, too. The key here is more powerful and more portable batteries, with at least five times the energy capacity for a given weight compared to today's lithium battery that powers your laptop. But why stop there? The theoretical potential is even higher, a tenfold im- provement with new materials, which would make batteries a replacement for gasoline even on long trips. The challenge is new battery electrode materials that haven't yet been explored, combining structure, composition and surface morphology to enhance their capacity and lifetimes; or else new materials that can store hydrogen at densities greater than liquid hydrogen combined with advanced, low-weight fuel cells that together are, in effect, a novel high-energy battery.

\section{Geological Carbon Sequestration}

One way to avoid the climate impact of emissions from coal or other fossil fuels burned to generate electric power is to capture the resulting carbon dioxide and inject it into the earth, where it might be stored for hundreds of years, or even longer. It's easier said than done, however, because of difficulties in capturing the gas efficiently, the vast volumes of fluid that must be sequestered, and concern about what will happen after the carbon dioxide is pumped into the ground. Before carbon dioxide sequestration can become a large-scale industry, critical questions must be answered. Can carbon dioxide be efficiently injected into tiny pores in rocks deep underground? How much of it would be released back to the atmosphere? Would release occur slowly or catastrophically? Can the carbon dioxide be confined to rock formations that have no other use; or might it leak into and permanently foul fresh water aquifers?

What is needed to answer these and other important questions are major scientific advances that will allow us to control the injection of carbon dioxide fluids into rock formations so that it goes where we want it to go, and stays there permanently with minimal negative impact on the subsurface environment. For example, carbon dioxide might be made to combine with water to form a more stable, dense fluid, or to combine with metal ions to make new minerals that will hold the carbon permanently. Such processes happening deep underground might be monitored remotely from the Earth's surface. To explore these opportunities requires a new level of understanding of the chemistry and physics that affects carbon dioxide fluids in rock formations. Such advanced understanding is achievable with advanced experimental tools that can probe minerals and fluids at the molecular level, and theoretical and computational capabilities that can be used to understand how nano-scale processes combine to produce the larger scale properties and processes that we observe. As a bonus, these new capabilities overlap with needs for managing radioactive waste storage in geologic reservoirs and creating enhanced geothermal energy production, both of which could expand climate-friendly U.S. energy production. 
Deployment, under this scenario, might have some interesting twists, as well. It may mean swapping batteries at your local service station just like people now swap propane tanks to power their grill and for the same reason-to avoid the fill-up wait, which might be hours for a battery. Alternatively, new electrochemical materials that enable "fast charge" are now being explored. Whether we charge batteries at night, swap them at the service station, or fast charge them on demand, it's an electric scenario that interconnects transportation and the grid.

\section{Making the Stories Come True}

These snapshots of a plausible future are scenarios, not predictions. But it's fair to ask: how do these energy futures feel? Are they where we'd like to go as a country, as a global civilization? They are more environmentally sustainable, and more affordable, too-because when renewable energy replaces fossil energy in a big way, it will be because it is more economical. Almost certainly better in national security terms, and not just for the United States: if every country can generate its own energy, then that's one less source of international tension. And the economic opportunity is huge-new investment and new jobs at home, vast international markets abroad. Wouldn't we like to sell China innovative high-tech energy technologies worth more than the commodities we buy from them? Let's be clear-achieving the energy

\section{Basic Materials Research to Commercial Impact: One Example}

A123 Systems, a Massachusetts company, owes its start to basic research on new lithium ion battery materials funded by the Office of Basic Energy Sciences in the U.S. Department of Energy. Beginning in 2002 with just a few grams of a prototype nanoscale lithium metal phosphate olivine from the laboratory of Professor Yet-Ming Chiang at MIT, the company quickly developed a commercial process for producing the high-performance cathode material that it calls Nanophosphate ${ }^{\mathrm{TM}}$, scaled powder production to tonnage quantities, and developed novel electrochemical cell designs taking advantage of the new cell chemistry. In November 2005, A123 announced the commercial production of a new class of high-power, safe, and long-lived lithium ion batteries. Concurrently, its first major commercialization partner, Black and Decker, announced a new line of DeWalt ${ }^{\mathrm{TM}}$ cordless power tools using this battery platform. This accomplishment, considered by many to be the fastest commercialization of a new battery chemistry in history, was further aided by a DOE Small Business Innovative Research (SBIR) grant received while the company was in its formative stages. Today, A123 is a global company that produces batteries and energy systems for three main markets: transportation, electric grid services,

and portable power. Assisted by development contracts from the United States Advanced Battery Consortium (USABC), a partnership between the DOE and U.S. automakers, A123 has developed hybrid electric vehicle (HEV) batteries using its core technology that are now being supplied to various customers in the transportation area. Subsequently, the company has started a second multimillion dollar US$A B C$ program focused on plug-in hybrid electric vehicle (PHEV) batteries, and is currently developing large (i.e., tractor-trailor sized) batteries for grid stabilization applications as well.

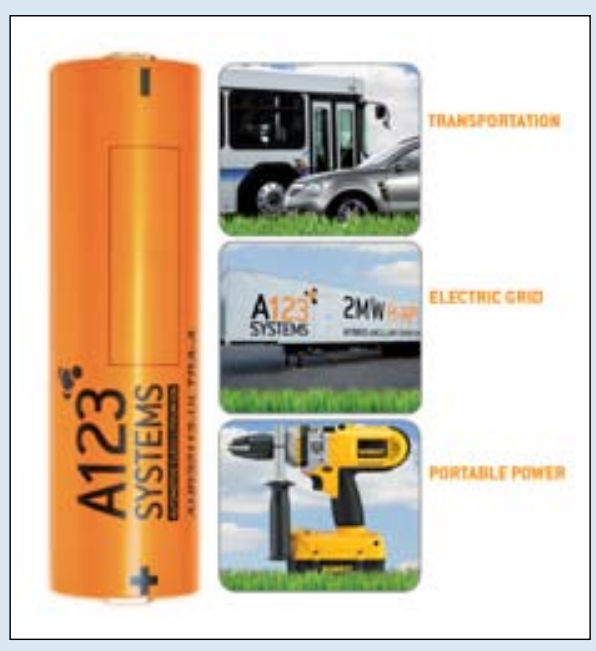

goals outlined here will not be easy, and for certain they won't happen without a major mobilization of fundamental science. But if we really want to achieve the intertwined energy goals outlined in this report, what other choice do we have? 


\section{New Science for a Secure and Sustainable Energy Future}

\section{The Path to Success}

Innovative new materials and chemical processes are the agents of change in achieving the vision. The energy systems of the future, whether they tap sunlight, store electricity, or make fuel from splitting water or reducing carbon dioxide, will revolve around materials and chemical changes that convert energy from one form to another. Such materials will need to be much smarter and more functional than today's energy materials. To control chemical reactions or to convert a solar photon to an electron requires coordination of multiple steps, each carried out by customized materials with designed nanoscale structures. Such advanced materials are not found in nature the way we find fossil fuels; they must be designed and fabricated to exacting standards using principles revealed by basic science.

Commercial silicon solar cells have gone from 6\% efficiency in 1954 to over $20 \%$ efficiency today, because basic materials research produced an understanding of the phenomena of photovoltaic conversion and continuously improved the semiconducting materials that perform this function. Conversion of sunlight to electricity is a complex process comprised of multiple constituent steps. Increasing the efficiency of the solar cell requires understanding the operation of each step: photon capture, charge separation and charge collection. Chargetrapping defects must be eliminated or minimized at each step, and the complex materials that execute each step must be integrated into a single functional unit. The same level of complexity in materials and chemical phenomena permeates all three energy goals - fuels from sunlight, electricity without carbon dioxide emissions, and revolutionary energy efficiency and use.

The task of creating materials with novel advanced properties and behaviors is enormously empowered by a parallel transformation now occurring in science: the rise of "control science" from observational science. The $20^{\text {th }}$ century

\section{The Opportunity of Control Science}

\section{Directing Matter and Energy at the Electronic, Atomic and Molecular Levels}

Science is now entering a new age based on the control of matter and energy at the electronic, atomic and molecular levels. During the $20^{\text {th }}$ century, science developed remarkable abilities to observe the world around us at ever-smaller length scales. By mid-century, electron microscopy revealed the intricate arrangements of atoms that determine the macroscopic behavior of materials in our everyday world. By the 1990s, scanning probe microscopes showed the electronic structure of individual atoms and interactions with neighboring atoms that control conducting, insulating and magnetic behavior. Intense x-ray and neutron sources allowed real time observation of changes in the atomic and electronic structures of materials as they underwent chemical reaction or responded to external stimuli.

In the $21^{\text {st }}$ century, observational science is giving birth to a new paradigm: directing the placement of atoms and the flow of energy to initiate and control chemical and physical phenomena in materials. We can now build materials atom by atom, opening new horizons for creating materials that do not occur in the natural world. Advanced theory and computational models predict the behavior of these hypothetical materials, and we can construct them in the laboratory by bottom up self-assembly and top-down lithography. Once synthesized, we can observe their behavior at the electronic and atomic levels and fine-tune their structures to optimize their properties. Such atomic and electronic control is a qualitatively new feature of basic science. It opens a new era where design can replace serendipity and materials can be developed atom by atom to accomplish targeted tasks. For the transition to greater energy sustainability, control science creates unprecedented opportunities to design and synthesize complex materials that direct the physical and chemical transformation of energy between light, electrons, and chemical bonds. 
witnessed revolutionary advances in observational science, bringing us remarkable discoveries such as high temperature superconductors, electron microscopy with atomic resolution, and carbon nanotubes that combine the strength of steel with the mass of a feather. Observational science is now giving birth to the science of control, where we use the accumulated knowledge derived from observations to design, initiate and direct the chemical and physical behavior of materials at atomic and nanoscales. Control science takes charge of the complexity of materials and chemical change, replacing serendipity with intention. The capability to design and implement the complex structures, compositions and chemical processes that control energy conversion is now within reach.

The intersection of control science with high-functioning materials creates a tipping point for sustainable energy.
Never has the impetus and the opportunity for sustainable energy been so great. A national initiative to apply the methods and tools of control science to complex materials and chemical processes will not only reduce and potentially eliminate our dependence on foreign energy, it will also establish our leadership position in next-generation energy technology and reap the economic benefits of supplying this technology to an energy-hungry world. 
The vision for a secure and sustainable energy future entails moving from spending hundreds of billions of dollars to import a third of our energy supply to the development, deployment and export of new carbon-free energy technologies invented and manufactured in the U.S. This is no small undertaking, but the opportunity is enormous. What is needed to make this future actually happen? However energy supply and use patterns change, all visions for the future include a huge increase in carbon-free energy sources, including renewable sources such as solar energy, as well as significant advances in energy efficiency. The trouble is that today's solutions are not up to the task - their present performance is well below what is needed and the rate at which improvements are being made is simply too slow. They must be propelled forward by paradigm-changing breakthroughs: new ideas that change "the rules of the game." This is the role that the DOE Office of Basic Energy Sciences (BES) will play: supporting fundamental game-changing discoveries and innovations that are the foundations for whole new technologies, as well as providing technical solutions to overcome fundamental scientific barriers with existing technologies. Of course, others must do their part, too. Engineers, entrepreneurs, venture capitalists and scientists will all need to work together to create the energy technologies of tomorrow, to commercialize these discoveries, and bring them to market. But without increasing the rate of discovery and innovation, the needed changes may never come, and if they do, they may be realized too late.

BES can uniquely address the challenge. Its mission supports the fundamental research that provides the basis for new and improved energy technologies as well as for mitigating the environmental impacts of energy use. In support of this mission, BES designs and constructs the necessary scientific tools and facilities that probe materials and chemical processes with unprecedented resolution, and so serves the research needs of the university, national laboratory, and industrial communities. Now, through eleven Basic Research Needs workshops and reports and the Grand Challenges report, BES has methodically documented the research agenda and the tools that are needed to address the single greatest scientific challenge the U.S. faces today. While the details are intricate, the conclusions are clear:

- A significant increase in the rate of discovery, innovation and technological change is needed. BES must lead a bold new initiative focused on solving the critical scientific roadblocks in next-generation, carbon-free energy technologies.

- Significant discoveries will come at the intersection of control science with advanced materials and chemical phenomena, and there is a clear firstmover advantage to those who focus their research efforts here. BES must lead U.S. energy research efforts in this direction lest the U.S. fall behind in global competition for discoveries of future energy sources and systems.

- It will take "dream teams" of highly educated talent, equipped with forefront tools, and focused on the most pressing challenges to increase the rate of discovery. BES must lead the development of these dream teams to close gaps between needs and capabilities in synthesis, characterization, theory, and computation of advanced materials.

- U.S. leadership requires BES to lead a national effort to aggressively recruit the best talent through a series of workforce development and early career programs aimed at inspiring today's students and young researchers to be the discoverers, inventors, and innovators of tomorrow's energy solutions. 



\section{DISCLAIMER}

This report was prepared as an account of work sponsored by an agency of the United States Government. Neither the United States government nor any agency thereof, nor any of their employees, makes any warranty, express or implied, or assumes any legal liability or responsibility for the accuracy, completeness, or usefulness of any information, apparatus, product, or process disclosed, or represents that its use would not infringe privately owned rights. Reference herein to any specific commercial product, process, or service by trade name, trademark, manufacturer, or otherwise, does not necessarily constitute or imply its endorsement, recommendation, or favoring by the United States Government or any agency thereof. The views and opinions of authors expressed herein do not necessarily state or reflect those of the United States Government or any agency thereof.

The report is available online at http://www.sc.doe.gov/bes/reports/list.html.

Publishing support services provided by Argonne National Laboratory 
us onsersuturos ENERGY 